\title{
USHERING IN THE STUDY AND TREATMENT OF PRECLINICAL ALZHEIMER DISEASE
}

\author{
Jessica B.S. Langbaum ${ }^{1}$, Adam S. Fleisher ${ }^{1}$, Kewei Chen ${ }^{1}$, Napatkamon Ayutyanont ${ }^{1}$, \\ Francisco Lopera ${ }^{2}$, Yakeel T. Quiroz ${ }^{3}$, Richard J. Caselli ${ }^{4}$, Pierre N. Tariot ${ }^{1}$, and Eric M. \\ Reiman $^{1,{ }^{*}}$ \\ ${ }^{1}$ Banner Alzheimer's Institute, 901 East Willetta Street, Phoenix, AZ 85006 \\ ${ }^{2}$ Grupo de Neurociencias de Antioquia, Universidad de Antioquia, Calle 62 No. 52 - 59, Medellín, \\ Colombia \\ ${ }^{3}$ Department of Psychiatry, Massachusetts General Hospital, 55 Fruit Street, Boston, MA 02114 \\ ${ }^{4}$ Department of Neurology, Mayo Clinic Arizona, 13400 East Shea Boulevard, Scottsdale, AZ \\ 85259
}

\begin{abstract}
Researchers have begun to characterize the subtle biological and cognitive processes that precede the clinical onset of Alzheimer disease (AD), and to set the stage for accelerated evaluation of experimental treatments to delay the onset, reduce the risk of or completely prevent clinical decline. Here, we provide an overview of the experimental strategies, and brain imaging and cerebrospinal fluid biomarker measures that are used in early detection and tracking of $\mathrm{AD}$, highlighting at-risk individuals who could be suitable for preclinical monitoring. We discuss how these advances have contributed to reconceptualization of $\mathrm{AD}$ as a sequence of biological changes that occur during progression from preclinical $\mathrm{AD}$, to mild cognitive impairment and finally dementia, and we review recently proposed research criteria for preclinical AD. Advances in the study of preclinical AD have driven the recognition that efficacy of at least some AD therapies may depend on initiation of treatment before clinical manifestation of disease, leading to a new era of $\mathrm{AD}$ prevention research.
\end{abstract}

\section{Introduction}

\begin{abstract}
Alzheimer disease (AD) is the most common cause of dementia in older people, and takes a devastating toll on patients and families ${ }^{1}$. Owing to the growing number of people living to older ages, a considerable increase is expected in the number of older adults with $\mathrm{AD}^{2-4}$ unless we can find effective treatments. Concern is increasing that AD treatments in development may need to be started before clinical onset, when extensive evidence of disease pathology already exists, to exert their most profound benefit. ${ }^{5}$ This concern, together with recent efforts to detect and track cognitive, clinical and biomarker changes associated with the preclinical stages of $\mathrm{AD}$, has contributed to the interest in the evaluation
\end{abstract}


of preclinical AD treatments ${ }^{6-10}$, which we have previously defined ${ }^{6}$ as "interventions that are started in the absence of mild cognitive impairment (MCI) or dementia and intended to postpone the onset, reduce the risk of, or completely prevent the clinical stages of AD."

The pathogenic cascade of $\mathrm{AD}$ is thought to begin at least $1-2$ decades prior to cognitive impairment, starting with accumulation of the amyloid- $\beta_{1-42}\left(\mathrm{~A} \beta_{1-42}\right)$ peptide (the major constituent of neuritic plaques) into oligomeric and fibrillar assemblies. The cascade eventually leads to neuroinflammatory changes, synaptic dysfunction and loss, accumulation and phosphorylation of the microtubule-associated protein tau (the main constituent of neurofibrillary tangles) and, ultimately, to neuronal degeneration ${ }^{11}$. Research has also suggested that some of these processes can be assessed using brain imaging and fluid biomarkers ${ }^{12,13}$. Recent studies, however, have indicated that other changes might precede $\mathrm{A} \beta$ accumulation. Such studies found evidence of mitochondrial dysfunction, accumulation tau pathology at young ages ${ }^{14-16}$, and less temporal cortex grey matter and smaller hippocampi in infants at increased genetic susceptibility for $\mathrm{AD}$, raising the possibility that some changes may be developmental ${ }^{17}$, perhaps providing a starting point for the cascade noted above.

The International Working Group for New Research Criteria for the Diagnosis of $\mathrm{AD}^{18}$ and, more recently, working groups from the National Institute on Aging (NIA) and Alzheimer's Association (AA) have championed efforts to reconceptualize AD as a progressive sequence of pathophysiological stages, some of which can be assessed using biomarkers, and which roughly correspond to preclinical, mild cognitive impairment (MCI) and dementia stages. The NIA-AA proposed revised criteria for clinical diagnosis of $\mathrm{MCI}^{19}$ and dementia due to $\mathrm{AD}^{20}$, and research criteria were proposed for the preclinical stages of $\mathrm{AD}^{21}$. These provisional, hypothesis-driven research criteria include three staging categories (Table 1) and are intended to provide a common language for researchers, to facilitate comparison of findings from different laboratories, and to help set the stage for evaluation of preclinical $\mathrm{AD}$ treatments. Approximately one- third of cognitively normal older adults over the age of 70 have been suggested to meet NIA-AA criteria for preclinical AD (stages 1-3) ${ }^{22}$. Of these individuals, approximately $10 \%$ progress to a diagnosis of MCI or dementia within 1 year, and of those in stage $3,43 \%$ progress to $\mathrm{MCI}$ or dementia in this time frame. ${ }^{23}$

Brain imaging and other biomarker measures have had a considerable impact on the study of $\mathrm{AD}$, and are expected to have an important role in the effort to find effective preclinical $\mathrm{AD}$ therapies. In this article, we review well-established cognitive, brain imaging, and fluid biomarkers for preclinical detection and tracking of AD. We also discuss studies in genetic at-risk groups as well as longitudinal studies examining progression to the clinical stages of AD. Finally, we note how these efforts are helping to accelerate evaluation of preclinical $\mathrm{AD}$ treatments in cognitively unimpaired individuals who are at increased risk of $\mathrm{AD}$ according to genetic or biomarker findings.

\section{Measurement of AD biomarkers}

To date, the most well-established measurements for detection and tracking of the preclinical and clinical stages of AD include structural (MRI measurements of regional and 
whole-brain tissue shrinkage, fluorodeoxyglucose (FDG) PET measurements of decline in the regional cerebral metabolic rate for glucose $(\mathrm{CMRgl})$, PET measurements of fibrillar amyloid- $\beta$ (A $\beta$ ) burden, and cerebrospinal fluid (CSF) measures of $A \beta_{1-42}$, total tau (t-tau) and phospho-tau (p-tau $)^{24,25}$ (Box 1). Other increasingly well-studied AD biomarkers include functional connectivity MRI (fcMRI) and task-related functional MRI. Notably, information provided by these and other biomarker measures depends not only on the modality used, but on the manner in which the data are acquired and analysed.

\section{Structural MRI}

Structural MRI has been the most extensively used brain imaging method in the detection and tracking of $\mathrm{AD}$, and shows establishment of brain atrophy at the time of diagnosis dementia due to $\mathrm{AD}$. These measurements also reveal that patients with $\mathrm{MCI}$ and dementia due to $\mathrm{AD}$ have accelerated rates of atrophy of the hippocampus, entorhinal cortex, regional grey matter, and whole brain ${ }^{26,27}$. Many of these measurements correlate with clinical severity ${ }^{28,29}$, subsequent clinical decline ${ }^{29,30}$, and neuronal loss ${ }^{31}$. Moreover, these MRI changes are apparent before onset of clinical symptoms, with hippocampal volumes reduced by approximately $10 \%$ at least 3 years prior to diagnosis of dementia due to $\mathrm{AD}$, and atrophy beginning at least 5 years prior to the diagnosis ${ }^{27,32}$.

\section{FDG PET}

$\mathrm{AD}$ is associated with preferential CMRgl reductions in the precuneus, posterior cingulate, and parietotemporal cortex, some of which are apparent prior to onset of dementia, and extend to the frontal cortex and whole brain as disease severity progresses ${ }^{33}$. CMRgl abnormalities could be related to reductions in activity or density of terminal neuronal fields or perisynaptic glial cells ${ }^{34,35}$, metabolic dysfunction ${ }^{36,37}$, or a combination of these factors. CMRgl reductions are progressive, correlate with clinical severity and are predictive of subsequent clinical decline ${ }^{38}$.

\section{Fibrillar A $\beta$ PET}

PET measurements of fibrillar $A \beta$ deposition could help to advance the study of AD by enabling in vivo measurement of fibrillar amyloid in the brain ${ }^{39}$. Clinically affected patients with $\mathrm{AD}$ show fibrillar $\mathrm{A} \beta$ deposition in the precuneus, posterior cingulate, parietal, temporal and frontal cortices, which mostly occurs in early disease stages, with fibrillar $\mathrm{A} \beta$ levels likely stabilizing later in the disease ${ }^{40}$. Cortical fibrillar amyloid seen with PET imaging correlates closely with amyloid pathology at autopsy ${ }^{41,42}$.

\section{Functional connectivity MRI}

Resting state fcMRI allows characterization of neural network activity when an individual is not completing a task. The default mode network (DMN) represents a cluster of brain regions-predominantly consisting of midline and lateral frontal regions, medial and lateral parietal regions extending into the posterior cingulate-retrosplenial cortex-that have elevated activity in states of relative rest ${ }^{43}, 44$. Such regions seem to be suppressed during various cognitive activities, including encoding of new memories ${ }^{45,46}$. Reduced resting state connectivity ${ }^{47}$ and alterations in task-induced deactivation responses on functional 
MRI have been identified in normal ageing ${ }^{48,49}, \mathrm{MCI}^{46,50}$ and $\mathrm{AD}^{43,49}$ compared with younger, healthy controls.

The DMN overlaps anatomically with brain regions that have $\mathrm{A} \beta$ deposition $^{51-53}$, regional atrophy and areas of reduced white matter integrity as measured on MRI ${ }^{54}$, and reduced $\mathrm{CMRgl}$ as measured using FDG PET ${ }^{47}$. Moreover, the DMN overlaps with brain regions that rely on glucose beyond its usual role, referred to as "aerobic glycolysis" in adequately oxygenated tissue ${ }^{55}$. Given the spatial distribution of aerobic glycolysis in young adults (age 20-33 years-old) overlaps spatially with PET measurements of fibrillar A $\beta$ deposition, it is suggestive that aerobic glycolysis may have a role in preclinical $\mathrm{AD}$, though the biological processes remain to be clarified.

\section{Cerebrospinal fluid measures}

Measurement of CSF A $\beta_{42}$, particularly when combined with t-tau or p-tau 181 measures, is useful for establishment of a diagnosis in people with MCI or very mild dementia, and for prognostication $^{56}$. Clinically affected patients with AD have abnormally low CSF A $\beta_{42}$ levels, and elevated $\mathrm{p}$-tau $\mathrm{ta}_{181}$ and t-tau levels ${ }^{57,58}$. The reduction in CSF A $\beta_{42}$ may seem counterintuitive, but is thought to result from sequestration of $A \beta_{42}$ in amyloid plaques in the brain ${ }^{56}$. CSF changes precede clinical onset by over a decade ${ }^{59-61}$, and are associated with smaller whole-brain volumes in cognitively healthy adults ${ }^{60}$. Although CSF A $\beta_{42}$ levels are well-established in detection and differential diagnosis of $\mathrm{AD}^{62}$, this measure is not well correlated with disease duration or clinical severity ${ }^{63}$. Similarly, elevated t-tau is consistently reported in patients with clinical AD but is not closely associated with severity of dementia 56,64 .

\section{Detecting the earliest brain changes}

Several AD-associated biomarkers show changes years before onset of symptoms in individuals at increased genetic risk of $\mathrm{AD}$ (for example, carriers of the $\varepsilon 4$ allele of the apolipoprotein $\mathrm{E}(A P O E)$ gene ${ }^{65}$ and individuals with gene mutations that cause early-onset $\mathrm{AD}^{59}$ ) and those with Down syndrome ${ }^{66}$, as well as cognitively normal individuals who subsequently progressed to clinical $\mathrm{AD}^{67,68}$ Considerable research is this area has been done to date, although the need remains for continued cohort studies with large sample sizes, and head to head comparisons of identified biomarkers, in conjunction with development of new biomarkers, to determine the extent to which these measurements, alone or in combination with other factors, predict subsequent rates of clinical decline.

\section{The sequence of biomarker changes}

The hypothetical sequence of biomarker changes proposed by Jack and colleagues are thought to begin about 10-20 years prior to clinical onset with biomarker evidence of amyloid plaque deposition (reduced CSF A $\beta_{42}$ levels and increased fibrillar A $\beta$ PET measurements) ${ }^{12}, 13,59,61,69$. Other elements of the pathobiological cascade, however, might exist that have yet to be discovered. These changes are probably followed by biomarker evidence of neuronal dysfunction and synaptic loss, such as regional reductions in cerebral glucose metabolism as measured on PET, altered patterns of functional 
connectivity, alterations in regional brain activity during memory encoding and novel viewing tasks, and reductions in grey matter and cortical thickness as measured on MRI. Biomarker evidence of tau pathology, neurofibrillary tangles, neuronal degeneration, and neuronal loss seem to follow in the sequence of biomarker changes. These changes include elevated CSF t-tau and p-tau levels, and hippocampal atrophy on MRI.

The exact timing of biomarker changes can depend on many factors, including the analytical tools used, the underlying pathobiology, and the age at which participants are studied ${ }^{17}$. We and others have characterized early biomarker and cognitive changes associated with preclinical $\mathrm{AD}$ by studying individuals with different risk of $\mathrm{AD}$ on the basis of genetic background, biomarker evidence of $\mathrm{AD}$, or other factors. As part of these studies, the apparent longitudinal trajectory of cognitive and biomarker changes in these at-risk groups was mapped as the individuals progressed to clinical stages of $\mathrm{AD}$ or estimated based on years from anticipated age at clinical onset. Certainly there are a number of other risk factors for AD_including but not limited to age, family history, cardiovascular disease and diabetes - that, although important, are beyond the scope of this Review, given its focus on at-risk groups for preclinical treatment trials.

\section{Identification and study of at-risk individuals}

Apolipoprotein E: $A P O E$ is the major susceptibility gene for late-onset AD. In comparison with individuals with the $\varepsilon 3 \varepsilon 3$ genotype, the $\varepsilon 2$ allele is associated with decreased risk of late-onset $\mathrm{AD}$ and older age at dementia onset. By contrast, each additional copy of the $\varepsilon 4$ allele, which is found in about $25 \%$ of the population and about $60 \%$ of patients with $\mathrm{AD}$ dementia, is associated with higher risk of late-onset $\mathrm{AD}$ and younger age at dementia onset, and individuals with two copies of this allele have an especially high risk ${ }^{70,71}$. The number of other confirmed AD susceptibility genes continues to grow, but these genes are associated with comparatively modest effects on $\mathrm{AD}$ risk ${ }^{72-76}$.

As each $A P O E$ genotype is associated with a different level of risk of $\mathrm{AD}$, detection and tracking of cognitive and biomarker changes in individuals with these different genotypes can provide researchers with initial information about which preclinical AD biomarker (baseline measurement or change in measure) or combination of biomarkers is related to subsequent clinical onset, without having to wait several years to obtain such information in unselected populations.

Studies of cognitively unimpaired individuals who carry at least one copy of the APOE \&4 allele show considerable differences in AD biomarkers compared with noncarriers, including MRI-measured accelerated cortical thining ${ }^{77}$, lower grey matter density ${ }^{78}$, and accelerated brain atrophy ${ }^{79}$. Some changes in brain structure are apparent during infancy in $\varepsilon 4$ carriers $^{17}$, although the relationship between such changes and development of $\mathrm{AD}$ dementia remains uknown. FDG PET studies of cognitively unimpaired APOE $\varepsilon 4$ carriers reported reduced CMRgl in the same posterior cingulate, precuneus, parietal, temporal and frontal regions as in $\mathrm{AD}$ dementia ${ }^{80-85}$, some of which are apparent almost 50 years prior to the expected onset of symptoms ${ }^{86}$, are progressive ${ }^{87}$, and are correlated with $\varepsilon 4$ allele dose $^{88}$. Recent evidence suggests that the preclinical hypometabolism in the posterior cingulate precedes hippocampal volume loss associated with $A P O E \varepsilon 4$ allele dose ${ }^{89}$, and 
some findings in cognitively normal older adults (average age 75 years) with greater amyloid deposition and in patients with MCI and Down syndrome, irrespective of APOE, suggest that hypermetabolism may precede metabolic decline in certain brain regions ${ }^{90-92}$.

A study of adults (49-79 year-old) APOE $\varepsilon 4$ carriers reported a pattern of reduced deactivation while performing a semantic categorization task compared with noncarriers, consistent with the DMN, though there was no allele dose effect ${ }^{93}$. Similarly, relative to age-matched non-carriers, differences in resting state connectivity were detected in both older adult (50-65 year-old) ${ }^{94}$ and young (20-35-year-old) ${ }^{95}$ APOE $\varepsilon 4$ carriers.

Amyloid PET studies of cognitively unimpaired adult $A P O E \varepsilon 4$ carriers found substantial fibrillar $\mathrm{A} \beta$ deposition in brain regions affected by $\mathrm{AD}$ pathology, including frontal, temporal, posterior cingulate-precuneus, and parietal regions compared with noncarriers ${ }^{69}$, 96-101. Fibrillar $A \beta$ deposition is correlated with $\varepsilon 4$ allele dose ${ }^{96}$, is apparent approximately 10-15 years prior to estimated onset of $\mathrm{AD}$ dementia, and might be associated with greater cognitive impairment in $\varepsilon 4$ carriers ${ }^{97,102,103}$. Differences in CSF measures of $\mathrm{A} \beta$ and tau have been reported, with $A P O E \varepsilon 4$ carriers having reduced $\mathrm{A} \beta_{42}{ }^{85}, 101,104-106$, elevated $A \beta_{40} / A \beta_{42}$ ratios ${ }^{107}$, and higher $\mathrm{t}$-tau and $\mathrm{p}$-tau $181{ }^{106,108,109}$ compared with noncarriers.

In addition to tracking biomarker changes in cognitively unimpaired $A P O E \& 4$ carriers, we and others have also examined the cognitive differences between carriers and noncarriers. Differences have not been consistently identified in early-life ${ }^{110}$ but, starting in late-middle age, decline in long-term recall memory performance is more prominent in APOE $\varepsilon 4$ carriers ${ }^{11-114}$ and is associated with $\varepsilon 4$ allele dose ${ }^{115,116}$, despite having no apparent clinical symptoms.

Autosomal dominant Alzheimer disease: More than 200 mutations of the presenilin 1 (PSEN1), presenilin 2 (PSEN2), and amyloid precursor protein (APP) genes have been shown to cause autosomal dominant $\mathrm{AD}(\mathrm{ADAD})^{117}$. As carriers of the genes will almost certainly develop $\mathrm{AD}$, they provide a unique group in which to characterize the trajectory of preclinical AD changes in relationship to their family's estimated age at clinical onset ${ }^{118}$. ADAD differs from the more common, late-onset form of AD in several respects-for example, by a generally younger age at clinical onset and overproduction rather than reduced clearance of $A \beta_{1-42}{ }^{119,120}$, though the question of overproduction versus clearance is still under study ${ }^{121}$. The two forms of $\mathrm{AD}$ do, however, have common features, particularly in regard to clinical phenotype ${ }^{122,123}$. Investigation of ADAD, therefore, provides another approach to preclinical study of AD.

Autosomal dominant versus sporadic AD: Findings from biomarker studies of cognitively unimpaired $\mathrm{ADAD}$ mutation carriers are generally consistent with those from cognitively unimpaired $A P O E \& 4$ carriers, although the exact timing and patterns (for example, fibrillar $\mathrm{A} \beta$ deposition) can differ. Comparison between $\mathrm{ADAD}$ and groups who are genetically atrisk of sporadic $\mathrm{AD}$ —in this case, $A P O E \& 4$ carriers - is important for determination of how findings from trials in $\mathrm{ADAD}$ carriers relate to sporadic $\mathrm{AD}$, given the planned preclinical treatment trials, discussed below. 
Cognitively unimpaired, young adult ADAD mutation carriers can have reduction in grey matter volume as measured by voxel-based techniques ${ }^{124,125}$ in the same brain regions preferentially affected by $\mathrm{AD}$, even before CSF or PET evidence of $\mathrm{A} \beta_{42}$ deposition ${ }^{61}$, with changes in hippocampal volume apparent approximately 15 years before expected symptom onset $^{59,126}$ that continue to decline over time ${ }^{127}$. Research by the Dominantly Inherited Alzheimer Network (DIAN) will be crucial in teasing apart the timing and trajectory of MRI changes, although to date it has only reported findings in regard to hippocampal volume ${ }^{59}$. Studies in ADAD mutation carriers have also reported CMRgl reductions in the posterior cingulate, precuneus, parietal, and temporal cortex at least 10 years prior to expected symptom onset ${ }^{59,128-130 .}$

Findings in amyloid PET studies to determine the pattern and timing of preclinical fibrillar $\mathrm{A} \beta$ deposition are generally similar in ADAD mutation carriers and APOE $\varepsilon 4$ carriers, with deposition apparent approximately 10 years prior to the expected age at clinical onset ${ }^{59,61}$. Some studies, however, have reported preferential deposition in the striatum in at least certain ADAD mutations ${ }^{131,132}$. A notable difference, highlighted by data from DIAN, is that in clinically affected ADAD mutation carriers, fibrillar $\mathrm{A} \beta$ deposition may continue to rise after clinical onset of $\mathrm{AD}$. Conversely, this finding has not been replicated in the PSEN1 E280A kindred ${ }^{61}$, perhaps owing to the difference in fibrillar A $\beta$ patterns observed with different ADAD mutations. In cognitively unimpaired ADAD mutation carriers, the direction of CSF A $\beta$ differences between carriers and noncarriers seems to depend on the age of participants, though the assay and batching of samples likely also play an important role. For example, in a recent study by our group, young adult PSEN1 E280A mutation carriers had significantly higher CSF A $\beta_{42}$ levels and significantly lower CSF t-tau/A $\beta_{42}$ and $\mathrm{p}$-tau/A $\beta_{42}$ ratios compared with kindred non-carriers ${ }^{125}$, in contrast to most findings reported in older preclinical individuals and in the clinical stages of late-onset $\mathrm{AD}$ and autosomal dominant $\mathrm{AD}^{63,133}$. Findings from the DIAN study, which involved a larger number individuals of different mutations at different ages, has suggested that CSF A $\beta_{42}$ levels begin to decline 25 years before their estimated age at clinical onset. The researchers did not, however, detect differences in CSF, plasma, or brain imaging measures between the 13 carriers and 13 non-carriers who were studied more than 20 years before their estimated age at clinical onset, perhaps owing to the small sample size ${ }^{59}$. Similar to findings in APOE $\varepsilon 4$ carriers, cognitive decline-including changes in memory, visuospatial and executive function - was reported in ADAD mutation carriers despite ongoing normal clinical status $^{134-138}$.

Other at-risk individuals: Individuals with biomarker evidence of AD pathology but no clinical symptoms represent another group in which to track the trajectory of preclinical AD. Amyloid PET studies suggested that approximately one-third of cognitively unimpaired older adults have significant fibrillar $A \beta$ deposition, which is consistent with intermediate or high likelihood of pathological $\mathrm{AD}^{69,98,139-141}$, with most of the rise in deposition occurring during the preclinical stage of $\mathrm{AD}^{142}$. Notably, most studies report that cognitive function is normal or only mildly affected in older individuals with PET evidence of A $\beta$ deposition $^{98,143-145}$, and that $\mathrm{A} \beta$ deposition could be more closely associated with 
longitudinal cognitive decline in older adults, particularly in regard to episodic memory ${ }^{146-149}$.

\section{Predicting clinical progression}

Retrospective and longitudinal studies have been helpful for tracking of changes that occur from preclinical $\mathrm{AD}$ to $\mathrm{AD}$ dementia. For example, retrospective analyses of individuals who eventually progressed to AD dementia have generally reported decline in memoryparticularly episodic, semantic and working memory - to be a defining feature of preclinical $\mathrm{AD},{ }^{150,151}$, with the rate of cognitive decline and affected domains greatly accelerating 5-6 years prior to diagnosis of dementia ${ }^{152}$. Importantly, cognitive decline in older age may be specific to those who progress to $\mathrm{MCI}$ or $\mathrm{AD}$ dementia and might not be an inevitable part of ageing per se $\mathrm{e}^{152}$, supporting the utility of cognition as a predictive marker of clinical progression. We and others have been particularly interested in determining the optimal combination of cognitive assessments for tracking cognitive decline prior to clinical progression of $\mathrm{AD}^{153-155}$.

\section{Non-biomarker-enriched populations}

$\mathrm{AD}$ biomarkers could be useful for prediction of clinical $\mathrm{AD}$ progression in populations who are not selected on the basis of AD biomarker profiles. For example, people with MCI who subsequently progress to probable $\mathrm{AD}$ dementia show significantly greater declines in CMRgl (measured on FDG PET) in AD-related brain regions than do individuals with MCI who remain stable during the same time interval ${ }^{156,157}$. MRI-measured reductions in hippocampal and entorhinal cortex volume parallel very early memory decline and are associated with subsequent progression to $\mathrm{MCI}$ or $\mathrm{AD}$ dementia $^{30,158,159}$.

Functional connectivity MRI could also be useful in predicting conversion from MCI to AD dementia ${ }^{160,161}$. Increased activity in "task positive" networks (as opposed to brain networks that deactivate during tasks such, as the DMN) in patients with MCI or AD dementia have been interpreted as attempts at compensation, although this hypothesis remains to be demonstrated conclusively. Alternative explanations include dedifferentiation of cortical function and aberrant excitation - a finding that has also been seen in animal models of $\mathrm{AD}^{162}$. In addition, lifelong patterns of increased brain activity might themselves predispose an individual to $A \beta$ deposition ${ }^{163}$. The latter hypothesis is intriguing, particularly given that $\mathrm{A} \beta$ deposition, as measured by amyloid PET, is associated with longitudinal cognitive decline in some normal adults and with progression to AD dementia ${ }^{68,98}$. As clinical progression occurs, however, $\mathrm{A} \beta$ accumulation slows ${ }^{98,159}$ and probably plateaus by the time of diagnosis of AD dementia ${ }^{164}$. Similar to functional MRI, elevated ratios of CSF tau $/ A \beta_{42}$ and $p$-tau/ $A \beta_{42}$ are predictive of subsequent clinical progression in preclinical $A D$ or MCI to AD dementia ${ }^{63,165}$. Together, positivity for PET and CSF measures of $A \beta$ seem to confer a threefold to fivefold higher likelihood of progression from preclinical AD or MCI to AD dementia ${ }^{166-171}$.

Biomarker-enriched populations-Several studies have examined clinical outcomes in individuals with biomarker evidence of AD pathology. Multiple positive AD biomarkers might have additive predictive value. For instance, in people with MCI, having abnormal 
CSF t-tau and p-tau concentrations and hippocampal atrophy predicted time to AD dementia ${ }^{172}$. Similarly, lower CSF A $\beta_{42}$ concentration, hypometabolism as measured on FDG PET, and hippocampal atrophy were associated with a faster time to AD dementia in people with $\mathrm{MCI}^{173}$, supporting the hypothetical dynamic biomarker model discussed previously ${ }^{12,13}$. Moreover, in the latter study, people with MCI who were positive for all of the three $\mathrm{AD}$ biomarkers consistently progressed to $\mathrm{AD}$ dementia during a 3-year period, whereas those with no positive biomarkers were unlikely to progress. These findings in MCI are supported by findings in cognitively normal individuals in which abnormal amyloid levels on PET imaging and CSF biomarkers, when examined together, are associated with faster time to cognitive impairment, whereas no differences were identified in the predictive value of individual biomarkers ${ }^{174}$.

\section{Preclinical AD populations}

In preclinical $\mathrm{AD}$ populations, high $\mathrm{A} \beta$ levels on PET imaging correlates with decreased performance on episodic memory and language assessments ${ }^{148}$ and increased hippocampal atrophy rate ${ }^{175}$ over 18 months. Additional follow-up is needed to assess the predictive value of high abnormal amyloid levels on PET imaging in cognitively healthy individuals for progression to $\mathrm{MCI}$ or $\mathrm{AD}$ dementia.

An important related issue is determination of the cut-off value that defines 'amyloid positivity'. A level could be selected that is consistent with an intermediate to high likelihood of $\mathrm{AD}$ pathology, or one that signifies the presence of any $\mathrm{A} \beta$ above that observed in low-risk (young APOE $\varepsilon 4$ noncarriers) individuals ${ }^{176}$. The optimal approach probably depends on the question being explored. An intermediate value between these two cut-offs could be a suitable approach for tracking change over time—something that is particularly important as the field begins preclinical AD treatment trials in biomarker-enriched populations-but researchers will need to ensure that this cut-off is associated with a high likelihood of progression to AD.

\section{Needs, challenges and opportunities}

\section{Biomarkers of preclinical-treatment response}

As growing evidence from natural history studies indicates that brain imaging and other biomarker measurements begin to change years before clinical symptoms emerge, it is plausible that these measures could have a role in evaluation of preclinical AD treatments. However, as we enter this era in $\mathrm{AD}$ prevention research and treatment trials, it is important to examine how biomarkers behave in response to treatment, irrespective of what is suggested by longitudinal data in observational studies. Prominent examples of unexpected biomarker responses to experimental treatment include MRI-measured brain shrinkage in response to the anti-A $\beta$ vaccination AN-1792 (despite possible cognitive benefit on a subset of memory measures $)^{177}$ and in response to the passive $A \beta$ immunotherapy bapineuzumab. Crucially, therefore, trials should incorporate all the established AD biomarker measures to determine how they behave in response to treatment. 


\section{Refining and expanding biomarker knowledge}

Observational longitudinal cohort studies stand to make important contributions to the field of preclinical AD biomarkers. For example, they are needed to improve our understanding of the trajectory of biomarker changes, enabling determination of the accuracy of prevailing hypotheses regarding the sequence of biomarker changes, and identification of which biomarkers, alone or in combination, predict subsequent clinical course. Additionally, new biomarkers are needed to detect other aspects of disease pathology and process and, if developed, could help in evaluation of potential treatments throughout the disease spectrum. Examples of needed biomarkers include those for assessment of oligomeric $\mathrm{A} \beta$ species, tau burden, and neuroinflammation, and more-specific measures of synaptic density.

\section{Preclinical treatment trials}

A number of preclinical treatment trials are in the planning stages or are already under way in several at-risk populations of cognitively unimpaired individuals-namely, individuals with biomarker evidence of $A \beta$ as measured by amyloid PET, individuals who carry ADAD mutations, those who are homozygous for the APOE 84 allele, and individuals with variablelength polymorphisms in TOMM4O. Although observational studies conducted to date have been valuable in preparing researchers for preclinical treatment trials, an important point to consider is that prevalence estimates of factors such as amyloid burden in older adults, which are derived from population-based studies, might not be observed in clinical trials owing to recruitment biases.

Over the next several years, the field will certainly see more trials as a result of initiatives including, but not limited to, the National Alzheimer's Project Act, the French Alzheimer Plan, and Alzheimer Europe. These prevention trials, which will embed currently available $\mathrm{AD}$ biomarkers among sensitive composite cognitive test scores, are designed to show that the treatment effects on biomarker measures are reasonably likely to predict clinical benefit, with the intent that one or more of these biomarkers may receive regulatory agency qualification as a surrogate end point for use in preclinical AD treatment trials ${ }^{5-7}$. In some cases, all of the data and biological samples will be made available to the scientific community following trial completion, with the aim of accelerating development of new biomarkers and sensitive data analysis methodologies. Moreover, these trials should provide a better test of the amyloid hypothesis than do trials in AD dementia or MCI.

\section{Conclusions}

The pathogenic cascade of $\mathrm{AD}$ is thought to begin at least 10-20 years prior to cognitive impairment, and $\mathrm{AD}$ biomarkers have played a crucial role in the detection and tracking of the preclinical and clinical stages of AD. As we begin this era of AD prevention research, biomarkers and sensitive cognitive measures are poised to continue to make important contributions. For instance, AD biomarkers, alone or in combination, could provide both scientific advances and regulatory approval for treatments under "Accelerated Approval provisions" or under the standard approval process if the biomarker has been validated to predict clinical benefit. Although there is no guarantee that treatments in the development pipeline will be effective, interest is growing in evaluation of these treatments in the 
preclinical stage of $\mathrm{AD}$. Given the potential benefits to society if an effective $\mathrm{AD}$ or preclinical AD treatment is found, researchers and other involved parties should have a sense of urgency. Moreover, this enthusiasm needs to be shared with the general public, informing them how to volunteer in prevention-focused research, given the likelihood that for every prevention trial, thousands of individuals will need to be screened in order to find enough eligible participants. With these factors in mind, we will be better prepared to deal with the complexities and uncertainties that lay ahead.

\section{Acknowledgments}

This article was supported by grants from the National Institute on Aging (R01AG031581 and P30AG19610 to EMR, RF1AG041705 to EMR, PNT and FL), the National Institute of Neurological Disorders and Stroke (F31NS078786 to YTQ), Colciencias (1115-493-26133, 1115-545-31651 and 1115-519-29028 FL), the Banner Alzheimer's Foundation, and the state of Arizona. We thank Drs. Nick Fox, Chris Rowe, and Michael Weiner and their colleagues for permission to use their images in Figure 2. We thank our valued research for their invaluable dedication and inspiration.

\section{Reference List}

1. Alzheimer's Association 2012 Alzheimer's disease facts and figures. Alzheimers Dement. 2012; 8:131-168. [PubMed: 22404854]

2. Corrada MM, Brookmeyer R, Paganini-Hill A, Berlau D, Kawas CH. Dementia incidence continues to increase with age in the oldest old: The 90+study. Ann. Neurol. 2010; 67:114-121. [PubMed: 20186856]

3. Brookmeyer R, et al. National estimates of the prevalence of Alzheimer's disease in the United States. Alzheimer's \& dementia: the journal of the Alzheimer's Association. 2011; 7(1):61-73.

4. Hebert LE, Beckett LA, Scherr PA, Evans DA. Annual incidence of Alzheimer disease in the United States projected to the years 2000 through 2050. Alzheimer Dis. Assoc. Disord. 2001; 15:169-173. [PubMed: 11723367]

5. Reiman, EM.; Langbaum, JBS. Brain imaging in the evaluation of putative Alzheimer's disease slowing, risk-reducing and prevention therapies. In: Jagust, WJ.; D'Esposito, M., editors. Imaging the Aging Brain. New York: Oxford University Press; 2009. p. 319-350.

6. Reiman EM, Langbaum JBS, Tariot PN. Alzheimer's Prevention Initiative: a proposal to evaluate presymptomatic treatments as quickly as possible. Biomarkers in Medicine. 2010; 4:3-14. [PubMed: 20383319]

7. Reiman EM, et al. Alzheimer's Prevention Initiative: a plan to accelerate the evaluation of presymptomatic treatments. J Alzheimers Dis. 2011; 25:293-301.

8. Bateman RJ, et al. Autosomal-dominant Alzheimer's disease: a review and proposal for the prevention of Alzheimer's disease. Alzheimers Res. Ther. 2011; 2:35.

9. Aisen PS, et al. Report of the task force on designing clinical trials in early (predementia) AD. Neurology. 2011; 76:280-286. [PubMed: 21178097]

10. Food and Drug Administration. Draft guidance. U.S Department of Health and Human Services, Food and Drug Administration, Center for Drug Evaluation and Research (CDER); 2013. Guidance for industry Alzheimer's disease: Developing drugs for the treatment of early stage disease.

11. Hardy J, Selkoe DJ. The amyloid hypothesis of Alzheimer's disease: progress and problems on the road to therapeutics. Science. 2002; 297:353-356. [PubMed: 12130773]

12. Jack CR Jr, et al. Hypothetical model of dynamic biomarkers of the Alzheimer's pathological cascade. Lancet Neurol. 2010; 9:119-128. [PubMed: 20083042]

13. Jack CR Jr, et al. Tracking pathophysiological processes in Alzheimer's disease: an updated hypothetical model of dynamic biomarkers. Lancet Neurol. 2013; 12:207-216. [PubMed: 23332364] 
14. Valla J, et al. Reduced posterior cingulate mitochondrial activity in expired young adult carriers of the APOE epsilon4 allele, the major late-onset Alzheimer's susceptibility gene. J. Alzheimers. Dis. 2010; 22:307-313. [PubMed: 20847408]

15. Braak H, Del TK. The pathological process underlying Alzheimer's disease in individuals under thirty. Acta Neuropathol. 2011; 121:171-181. [PubMed: 21170538]

16. Elobeid A, Soininen H, Alafuzoff I. Hyperphosphorylated tau in young and middle-aged subjects. Acta Neuropathol. 2012; 123:97-104. [PubMed: 22160320]

17. Knickmeyer RC, et al. Common Variants in Psychiatric Risk Genes Predict Brain Structure at Birth. Cereb. Cortex. 2013

18. Dubois B, et al. Revising the definition of Alzheimer's disease: a new lexicon. Lancet Neurol. 2010; 9:1118-1127. [PubMed: 20934914]

19. Albert MS, et al. The diagnosis of mild cognitive impairment due to Alzheimer's disease: Recommendations from the National Institute on Aging and Alzheimer's Association workgroup. Alzheimers Dement. 2011; 7:270-279. [PubMed: 21514249]

20. McKhann GM, et al. The diagnosis of dementia due to Alzheimer's disease: Recommendations from the National Institute on Aging and the Alzheimer's Association workgroup. Alzheimers Dement. 2011; 7:263-269. [PubMed: 21514250]

21. Sperling RA, et al. Toward defining the preclinical stages of Alzheimer's disease: Recommendations from the National Institute on Aging and the Alzheimer's Association workgroup. Alzheimers Dement. 2011; 7:280-292. [PubMed: 21514248]

22. Jack CR Jr, et al. An operational approach to National Institute on Aging-Alzheimer's Association criteria for preclinical Alzheimer disease. Ann Neurol. 2012; 71:765-775. [PubMed: 22488240]

23. Knopman DS, et al. Short-term clinical outcomes for stages of NIA-AA preclinical Alzheimer disease. Neurology. 2012; 78:1576-1582. [PubMed: 22551733]

24. Reiman EM, Jagust WJ. Brain imaging in the study of Alzheimer's disease. Neuroimage. 2012; 61:505-516. [PubMed: 22173295]

25. de Leon MJ, et al. Imaging and CSF studies in the preclinical diagnosis of Alzheimer's disease. Ann N Y. Acad Sci. 2007; 1097:114-145. [PubMed: 17413016]

26. Dickerson BC, et al. MRI-derived entorhinal and hippocampal atrophy in incipient and very mild Alzheimer's disease. Neurobiol. Aging. 2001; 22:747-754. [PubMed: 11705634]

27. Johnson KA, Fox NC, Sperling RA, Klunk WE. Brain imaging in Alzheimer disease. Cold Spring Harb. Perspect. Med. 2012; 2:a006213. [PubMed: 22474610]

28. Jack CR Jr, et al. Prediction of AD with MRI-based hippocampal volume in mild cognitive impairment. Neurology. 1999; 52:1397-1403. [PubMed: 10227624]

29. Jack CR Jr, et al. Brain atrophy rates predict subsequent clinical conversion in normal elderly and amnestic MCI. Neurology. 2005; 65:1227-1231. [PubMed: 16247049]

30. Chetelat G, et al. Using voxel-based morphometry to map the structural changes associated with rapid conversion in MCI: a longitudinal MRI study. Neuroimage. 2005; 27:934-946. [PubMed: 15979341]

31. McGeer PL, et al. Comparison of PET, MRI, and CT with pathology in a proven case of Alzheimer's disease. Neurology. 1986; 36:1569-1574. [PubMed: 3491344]

32. Jack CR Jr, et al. Atrophy rates accelerate in amnestic mild cognitive impairment. Neurology. 2008; 70:1740-1752. [PubMed: 18032747]

33. Langbaum JBS, et al. Categorical and correlational analyses of baseline fluorodeoxyglucose positron emission tomography images from the Alzheimer's Disease Neuroimaging Initiative (ADNI). Neuroimage. 2009; 45:1107-1116. [PubMed: 19349228]

34. Schwartz WJ, et al. Metabolic mapping of functional activity in the hypothalamoneurohypophysial system of the rat. Science. 1979; 205:723-725. [PubMed: 462184]

35. Meguro K, et al. Neocortical and hippocampal glucose hypometabolism following neurotoxic lesions of the entorhinal and perirhinal cortices in the non-human primate as shown by PET. Implications for Alzheimer's disease. Brain. 1999; 122(Pt 8):1519-1531. [PubMed: 10430835] 
36. Magistretti PJ, Pellerin L. Cellular bases of brain energy metabolism and their relevance to functional brain imaging: evidence for a prominent role of astrocytes. Cereb. Cortex. 1996; 6:5061. [PubMed: 8670638]

37. Mark RJ, Pang Z, Geddes JW, Uchida K, Mattson MP. Amyloid beta-peptide impairs glucose transport in hippocampal and cortical neurons: involvement of membrane lipid peroxidation. J. Neurosci. 1997; 17:1046-1054. [PubMed: 8994059]

38. Silverman DH, et al. Positron emission tomography in evaluation of dementia: Regional brain metabolism and long-term outcome. Journal of the American Medical Association. 2001; 286:2120-2127. [PubMed: 11694153]

39. Klunk WE, et al. Imaging brain amyloid in Alzheimer's disease with Pittsburgh Compound-B. Ann Neurol. 2004; 55:306-319. [PubMed: 14991808]

40. Weiner MW, et al. The Alzheimer's Disease Neuroimaging Initiative: a review of papers published since its inception. Alzheimers Dement. 2012; 8:S1-S68. [PubMed: 22047634]

41. Clark CM, et al. Use of florbetapir-PET for imaging beta-amyloid pathology. Journal of the American Medical Association. 2011; 305:275-283. [PubMed: 21245183]

42. Clark CM, et al. Cerebral PET with florbetapir compared with neuropathology at autopsy for detection of neuritic amyloid-beta plaques: a prospective cohort study. Lancet Neurol. 2012; 11:669-678. [PubMed: 22749065]

43. Buckner RL, Vincent JL. Unrest at rest: default activity and spontaneous network correlations. Neuroimage. 2007; 37:1091-1096. [PubMed: 17368915]

44. Raichle ME, et al. A default mode of brain function. Proc. Natl. Acad. Sci. U. S. A. 2001; 98:676682. [PubMed: 11209064]

45. Pihlajamaki M, DePeau KM, Blacker D, Sperling RA. Impaired medial temporal repetition suppression is related to failure of parietal deactivation in Alzheimer disease. American Journal of Geraitric Psychiatry. 2008; 16:283-292.

46. Sorg C, et al. Selective changes of resting-state networks in individuals at risk for Alzheimer's disease. Proc Natl Acad Sci U S A. 2007; 104:18760-18765. [PubMed: 18003904]

47. Buckner RL, et al. Molecular, structural, and functional characterization of Alzheimer's disease: evidence for a relationship between default activity, amyloid, and memory. J Neurosci. 2005; 25:7709-7717. [PubMed: 16120771]

48. Andrews-Hanna JR, et al. Disruption of large-scale brain systems in advanced aging. Neuron. 2007; 56:924-935. [PubMed: 18054866]

49. Lustig C, et al. Functional deactivations: change with age and dementia of the Alzheimer type. Proc Natl Acad Sci U S A. 2003; 100:14504-14509. [PubMed: 14608034]

50. Rombouts SA, Barkhof F, Goekoop R, Stam CJ, Scheltens P. Altered resting state networks in mild cognitive impairment and mild Alzheimer's disease: an fMRI study. Hum Brain Mapp. 2005; 26:231-239. [PubMed: 15954139]

51. Sperling RA, et al. Amyloid deposition is associated with impaired default network function in older persons without dementia. Neuron. 2009; 63:178-188. [PubMed: 19640477]

52 . Hedden $\mathrm{T}$, et al. Disruption of functional connectivity in clinically normal older adults harboring amyloid burden. J. Neurosci. 2009; 29:12686-12694. [PubMed: 19812343]

53. Drzezga A, et al. Neuronal dysfunction and disconnection of cortical hubs in non-demented subjects with elevated amyloid burden. Brain. 2011; 134:1635-1646. [PubMed: 21490054]

54. Greicius MD, Supekar K, Menon V, Dougherty RF. Resting-state functional connectivity reflects structural connectivity in the default mode network. Cereb. Cortex. 2009; 19:72-78. [PubMed: 18403396]

55. Vlassenko AG, et al. Spatial correlation between brain aerobic glycolysis and amyloid-beta (Abeta) deposition. Proc. Natl. Acad. Sci. U. S. A. 2010; 107:17763-17767. [PubMed: 20837517]

56. Holtzman DM. CSF biomarkers for Alzheimer's disease: current utility and potential future use. Neurobiol. Aging. 2011; 32(Suppl 1):S4-S9. [PubMed: 22078172]

57. Thal LJ, et al. The Role of Biomarkers in Clinical Trials for Alzheimer Disease. Alzheimer Dis Assoc Disord. 2006; 20:6-15. [PubMed: 16493230] 
58. Fagan AM, et al. Cerebrospinal fluid tau/beta-amyloid(42) ratio as a prediction of cognitive decline in nondemented older adults. Arch Neurol. 2007; 64:343-349. [PubMed: 17210801]

59. Bateman RJ, et al. Clinical and Biomarker Changes in Dominantly Inherited Alzheimer's Disease. N Engl J Med. 2012

60. Fagan AM, et al. Decreased cerebrospinal fluid Abeta(42) correlates with brain atrophy in cognitively normal elderly. Ann Neurol. 2009; 65:176-183. [PubMed: 19260027]

61. Fleisher AS, et al. Florbetapir PET analysis of amyloid-b deposition in presenilin 1 E280A autosomal-dominant Alzheimer's disease kindred: a cross-sectional study. Lancet Neurol. 2012; 11:1057-1065. [PubMed: 23137949]

62. Sunderland T, et al. Decreased beta-amyloid1-42 and increased tau levels in cerebrospinal fluid of patients with Alzheimer disease. JAMA. 2003; 289:2094-2103. [PubMed: 12709467]

63. Fagan AM, et al. Cerebrospinal fluid tau/b-amyloid42 ratio as a prediction of cognitive decline in nondemented older adults. Arch Neurol. 2007; 64:343-349. [PubMed: 17210801]

64. Sunderland T, et al. Longitudinal stability of CSF tau levels in Alzheimer patients. Biol Psychiatry. 1999; 46:750-755. [PubMed: 10494442]

65. Reiman EM, et al. Preclinical evidence of Alzheimer's disease in persons homozygous for the e4 allele for apolipoprotein E. N. Engl. Med. 1996; 334:752-758.

66. Beacher F, et al. Brain anatomy and ageing in non-demented adults with Down's syndrome: an in vivo MRI study. Psychol. Med. 2009:1-9. [PubMed: 19335938]

67. Jack CR Jr, et al. Brain atrophy rates predict subsequent clinical conversion in normal elderly and amnestic MCI. Neurology. 2005; 65:1227-1231. [PubMed: 16247049]

68. Morris JC, et al. Pittsburgh Compound B imaging and prediction of progression from cognitive normality to symptomatic Alzheimer disease. Arch Neurol. 2009; 66:1469-1475. [PubMed: 20008650]

69. Rowe CC, et al. Amyloid imaging results from the Australian Imaging, Biomarkers and Lifestyle (AIBL) study of aging. Neurobiol. Aging. 2010; 31:1275-1283. [PubMed: 20472326]

70. Corder EH, et al. Gene dose of apolipoprotein E type 4 allele and the risk of Alzheimer's disease in late onset families. Science. 1993; 261:921-923. [PubMed: 8346443]

71. Saunders AM, et al. Association of apolipoprotein E allele epsilon 4 with late-onset familial and sporadic Alzheimer's disease. Neurology. 1993; 43:1467-1472. [PubMed: 8350998]

72. Roses AD, et al. A TOMM40 variable-length polymorphism predicts the age of late-onset Alzheimer's disease. Pharmacogenomics. J. 2010; 10:375-384. [PubMed: 20029386]

73. Naj AC, et al. Common variants at MS4A4/MS4A6E, CD2AP, CD33 and EPHA1 are associated with late-onset Alzheimer's disease. Nat Genet. 2011; 43:436-441. [PubMed: 21460841]

74. Hollingworth P, et al. Common variants at ABCA7, MS4A6A/MS4A4E, EPHA1, CD33 and CD2AP are associated with Alzheimer's disease. Nat Genet. 2011; 43:429-435. [PubMed: 21460840]

75. Guerreiro R, et al. TREM2 variants in Alzheimer's disease. N. Engl. J. Med. 2013; 368:117-127. [PubMed: 23150934]

76. Jonsson T, et al. Variant of TREM2 associated with the risk of Alzheimer's disease. N. Engl. J. Med. 2013; 368:107-116. [PubMed: 23150908]

77. Espeseth T, et al. Accelerated age-related cortical thinning in healthy carriers of apolipoprotein $\mathrm{E}$ epsilon 4. Neurobiol. Aging. 2008; 29:329-340. [PubMed: 17161508]

78. Wishart HA, et al. Regional brain atrophy in cognitively intact adults with a single APOE e4 allele. Neurology. 2006; 67:1221-1224. [PubMed: 17030756]

79. Chen K, et al. Correlations between apolipoprotein E e4 gene dose and whole brain atrophy rates. Am. J Psychiatry. 2007; 164:916-921. [PubMed: 17541051]

80. Reiman EM, et al. Preclinical evidence of Alzheimer's disease in persons homozygous for the epsilon 4 allele for apolipoprotein E. N Engl J Med. 1996; 334:752-758. [PubMed: 8592548]

81. Small GW, et al. Early detection of Alzheimer's disease by combining apolipoprotein $\mathrm{E}$ and neuroimaging. Ann N. Y. Acad. Sci. 1996; 802:70-78. [PubMed: 8993486] 
82. de Leon MJ, et al. Prediction of cognitive decline in normal elderly subjects with 2[(18)F]fluoro-2-deoxy-D-glucose/poitron-emission tomography (FDG/PET). Proc. Natl. Acad. Sci. U. S. A. 2001; 98:10966-10971. [PubMed: 11526211]

83. Langbaum JB, et al. Hypometabolism in Alzheimer-affected brain regions in cognitively healthy Latino individuals carrying the apolipoprotein E epsilon4 allele. Arch. Neurol. 2010; 67:462-468. [PubMed: 20385913]

84. Small GW, et al. Cerebral metabolic and cognitive decline in persons at genetic risk for Alzheimer's disease. Proc. Natl. Acad. Sci. U. S. A. 2000; 97:6037-6042. [PubMed: 10811879]

85. Lo RY, et al. Longitudinal change of biomarkers in cognitive decline. Arch Neurol. 2011; 68:1257-1266. [PubMed: 21670386]

86. Reiman EM, et al. Functional brain abnormalities in young adults at genetic risk for late-onset Alzheimer's dementia. Proc. Natl. Acad. Sci. U. S. A. 2004; 101:284-289. [PubMed: 14688411]

87. Reiman EM, et al. Declining brain activity in cognitively normal apolipoprotein E e4 heterozygotes: A foundation for using positron emission tomography to efficiently test treatments to prevent Alzheimer's disease. Proc. Natl. Acad. Sci. U. S. A. 2001; 98:3334-3339. [PubMed: 11248079]

88. Reiman EM, et al. Correlations between apolipoprotein E e4 gene dose and brain-imaging measurements of regional hypometabolism. Proc. Natl. Acad. Sci. U. S. A. 2005; 102:8299-8302. [PubMed: 15932949]

89. Protas HD, et al. Posterior cingulate glucose metabolism, hippocampal glucose metabolism, and hippocampal volume in cognitively normal, late-middle age persons at three levels of genetic risk for Alzheimer's disease. Arch Neurol. in press.

90. Cohen AD, et al. Basal Cerebral Metabolism May Modulate the Cognitive Effects of A $\{$ beta $\}$ in Mild Cognitive Impairment: An Example of Brain Reserve. J Neurosci. 2009; 29:14770-14778. [PubMed: 19940172]

91. Haier RJ, et al. Temporal cortex hypermetabolism in Down syndrome prior to the onset of dementia. Neurology. 2003; 61:1673-1679. [PubMed: 14694028]

92. Oh H, Habeck C, Madison C, Jagust W. Covarying alterations in Ab deposition, glucose metabolism, and gray matter volume in cognitively normal elderly. Human Brain Mapping. In Press.

93. Persson J, et al. Altered deactivation in individuals with genetic risk for Alzheimer's disease. Neuropsychologia. 2008; 46:1679-1687. [PubMed: 18346764]

94. Fleisher AS, et al. Resting-state BOLD networks versus task-associated functional MRI for distinguishing Alzheimer's disease risk groups. Neuroimage. 2009; 47:1678-1690. [PubMed: 19539034]

95. Filippini N, et al. Distinct patterns of brain activity in young carriers of the APOE-\{varepsilon 44 allele. Proc. Natl. Acad. Sci. U. S. A. 2009; 106:7209-7214. [PubMed: 19357304]

96. Reiman EM, et al. Fibrillar amyloid-b burden in cognitively normal people at three levels of genetic risk for Alzheimer's disease. Proc. Natl. Acad. Sci. U. S. A. 2009; 106:6820-6825. [PubMed: 19346482]

97. Pike KE, et al. Cognition and beta-amyloid in preclinical Alzheimer's disease: data from the AIBL study. Neuropsychologia. 2011; 49:2384-2390. [PubMed: 21529702]

98. Villemagne VL, et al. Longitudinal assessment of Abeta and cognition in aging and Alzheimer disease. Ann Neurol. 2011; 69:181-192. [PubMed: 21280088]

99. Mielke MM, et al. Indicators of amyloid burden in a population-based study of cognitively normal elderly. Neurology. 2012; 79:1570-1577. [PubMed: 22972644]

100. Fleisher AS, et al. Apolipoprotein E epsilon4 and age effects on florbetapir positron emission tomography in healthy aging and Alzheimer disease. Neurobiol. Aging. 2013; 34:1-12. [PubMed: 22633529]

101. Morris JC, et al. APOE predicts amyloid-beta but not tau Alzheimer pathology in cognitively normal aging. Ann. Neurol. 2010; 67:122-131. [PubMed: 20186853]

102. Kantarci K, et al. APOE modifies the association between Abeta load and cognition in cognitively normal older adults. Neurology. 2012; 78:232-240. [PubMed: 22189452] 
103. Lim YY, et al. Abeta amyloid, cognition, and APOE genotype in healthy older adults. Alzheimers Dement. 2012

104. Peskind ER, et al. Age and apolipoprotein $E^{*} 4$ allele effects on cerebrospinal fluid beta-amyloid 42 in adults with normal cognition. Arch Neurol. 2006; 63:936-939. [PubMed: 16831961]

105. Popp J, et al. Cerebrospinal fluid markers for Alzheimer's disease over the lifespan: effects of age and the APOEepsilon4 genotype. J. Alzheimers Dis. 2010; 22:459-468. [PubMed: 21084733]

106. Kester MI, et al. CSF biomarkers predict rate of cognitive decline in Alzheimer disease. Neurology. 2009; 73:1353-1358. [PubMed: 19858456]

107. Fagan AM, et al. Differences in the Abeta40/Abeta42 ratio associated with cerebrospinal fluid lipoproteins as a function of apolipoprotein E genotype. Ann. Neurol. 2000; 48:201-210. [PubMed: 10939571]

108. Glodzik-Sobanska L, et al. The effects of normal aging and ApoE genotype on the levels of CSF biomarkers for Alzheimer's disease. Neurobiol Aging. 2009; 30:672-681. [PubMed: 17920160]

109. Mosconi L, et al. Hypometabolism and altered cerebrospinal fluid markers in normal apolipoprotein E E4 carriers with subjective memory complaints. Biol. Psychiatry. 2008; 63:609_ 618. [PubMed: 17720148]

110. Ihle A, Bunce D, Kliegel M. APOE epsilon4 and cognitive function in early life: a meta-analysis. Neuropsychology. 2012; 26:267-277. [PubMed: 22329498]

111. Baxter LC, Caselli RJ, Johnson SC, Reiman E, Osborne D. Apolipoprotein E e4 affects new learning in cognitively normal individuals at risk for Alzheimer's disease. Neurobiol. Aging. 2003; 24:947-952. [PubMed: 12928055]

112. Caselli RJ, et al. Longitudinal changes in cognition and behavior in asymptomatic carriers of the APOE e4 allele. Neurology. 2004; 62:1990-1995. [PubMed: 15184602]

113. Lind J, et al. Reduced hippocampal volume in non-demented carriers of the apolipoprotein $\mathrm{E}$ epsilon4: relation to chronological age and recognition memory. Neurosci. Lett. 2006; 396:2327. [PubMed: 16406347]

114. Caselli RJ, et al. Cognitive domain decline in healthy apolipoprotein E epsilon4 homozygotes before the diagnosis of mild cognitive impairment. Arch Neurol. 2007; 64:1306-1311. [PubMed: 17846270]

115. Caselli RJ, et al. Longitudinal modeling of age-related memory decline and the APOE e4 effect. N. Engl. J. Med. 2009; 361:255-263. [PubMed: 19605830]

116. Caselli RJ, et al. Longitudinal modeling of frontal cognition in APOE e4 homozygotes, heterozygotes, and noncarriers. Neurology. 2011; 76:1383-1388. [PubMed: 21502596]

117. Alzheimer's Disease and Frontotemporal Dementia Mutation Database. 2013

118. Campion D, et al. Early-onset autosomal dominant Alzheimer disease: prevalence, genetic heterogeneity, and mutation spectrum. Am. J. Hum. Genet. 1999; 65:664-670. [PubMed: 10441572]

119. Cirrito JR, et al. P-glycoprotein deficiency at the blood-brain barrier increases amyloid-beta deposition in an Alzheimer disease mouse model. J. Clin. Invest. 2005; 115:3285-3290. [PubMed: 16239972]

120. Castellano JM, et al. Human apoE isoforms differentially regulate brain amyloid-beta peptide clearance. Sci Transl. Med. 2011; 3:89ra57.

121. Fukumoto H, Cheung BS, Hyman BT, Irizarry MC. Beta-secretase protein and activity are increased in the neocortex in Alzheimer disease. Arch Neurol. 2002; 59:1381-1389. [PubMed: 12223024]

122. Godbolt AK, et al. Sporadic and familial dementia with ubiquitin-positive tau-negative inclusions: clinical features of one histopathological abnormality underlying frontotemporal lobar degeneration. Arch Neurol. 2005; 62:1097-1101. [PubMed: 16009765]

123. Lleo A, Berezovska O, Growdon JH, Hyman BT. Clinical, pathological, and biochemical spectrum of Alzheimer disease associated with PS-1 mutations. Am. J. Geriatr. Psychiatry. 2004; 12:146-156. [PubMed: 15010344]

124. Quiroz Y, et al. Cortical signature of Alzheimer's disease-related thinning in presymptomatic presenilin-1 mutation carriers. Alzheimers Dement. 2011; 7:S220. 
125. Reiman EM, et al. Brain imaging and fluid biomarker analysis in young adults at genetic risk for autosomal dominant Alzheimer's disease in the presenilin 1 E280A kindred: a case-control study. Lancet Neurol. 2012

126. Fox NC, Warrington EK, Stevens JM, Rossor MN. Atrophy of the hippocampal formation in early familial Alzheimer's disease. A longitudinal MRI study of at-risk members of a family with an amyloid precursor protein 717Val-Gly mutation. Ann. N. Y. Acad. Sci. 1996; 777:226-232. [PubMed: 8624089]

127. Fox NC, et al. Presymptomatic hippocampal atrophy in Alzheimer's disease. A longitudinal MRI study. Brain. 1996; 119:2001-2007. [PubMed: 9010004]

128. Kennedy AM, et al. Deficits in cerebral glucose metabolism demonstrated by positron emission tomography in individuals at risk of familial Alzheimer's disease. Neurosci. Lett. 1995; 186:1720. [PubMed: 7783942]

129. Mosconi L, et al. Hypometabolism exceeds atrophy in presymptomatic early-onset familial Alzheimer's disease. J Nucl Med. 2006; 47:1778-1786. [PubMed: 17079810]

130. Scholl M, et al. Glucose metabolism and PIB binding in carriers of a His163Tyr presenilin 1 mutation. Neurobiol Aging. 2011; 32:1388-1399. [PubMed: 19796846]

131. Klunk WE, et al. Amyloid deposition begins in the striatum of presenilin-1 mutation carriers from two unrelated pedigrees. J Neurosci. 2007; 27:6174-6184. [PubMed: 17553989]

132. Villemagne VL, et al. High striatal amyloid beta-peptide deposition across different autosomal Alzheimer disease mutation types. Arch Neurol. 2009; 66:1537-1544. [PubMed: 20008660]

133. Ringman JM, et al. Cerebrospinal fluid biomarkers and proximity to diagnosis in preclinical familial Alzheimer's disease. Dement Geriatr Cogn Disord. 2012; 33:1-5. [PubMed: 22343824]

134. Parra MA, et al. Visual short-term memory binding deficits in familial Alzheimer's disease. Brain. 2010; 133:2702-2713. [PubMed: 20624814]

135. Arango-Lasprilla JC, Cuetos F, Valencia C, Uribe C, Lopera F. Cognitive changes in the preclinical phase of familial Alzheimer's disease. J Clin. Exp. Neuropsychol. 2007; 29:892-900. [PubMed: 17852592]

136. Newman SK, Warrington EK, Kennedy AM, Rossor MN. The earliest cognitive change in a person with familial Alzheimer's disease: presymptomatic neuropsychological features in a pedigree with familial Alzheimer's disease confirmed at necropsy. J. Neurol Neurosurg. Psychiatry. 1994; 57:967-972. [PubMed: 8057122]

137. Ringman JM, et al. Neuropsychological function in nondemented carriers of presenilin-1 mutations. Neurology. 2005; 65:552-558. [PubMed: 16116115]

138. Acosta-Baena N, et al. Pre-dementia clinical stages in presenilin 1 E280A familial early-onset Alzheimer's disease: a retrospective cohort study. Lancet Neurol. 2011; 10:213-220. [PubMed: 21296022]

139. Pike KE, et al. b-amyloid imaging and memory in non-demented individuals: evidence for preclinical Alzheimer's disease. Brain. 2007; 130:2837-2844. [PubMed: 17928318]

140. Johnson KA, et al. Florbetapir (F18-AV-45) PET to assess amyloid burden in Alzheimer's disease dementia, mild cognitive impairment, and normal aging. Alzheimers Dement. 2013

141. Mintun MA, et al. [11C]PIB in a nondemented population: potential antecedent marker of Alzheimer disease. Neurology. 2006; 67:446-452. [PubMed: 16894106]

142. Vlassenko AG, et al. Amyloid-beta plaque growth in cognitively normal adults: Longitudinal [11C]Pittsburgh compound B data. Ann Neurol. 2011; 70:857-861. [PubMed: 22162065]

143. Sperling RA, et al. Amyloid deposition detected with florbetapir F 18 ((18)F-AV-45) is related to lower episodic memory performance in clinically normal older individuals. Neurobiol. Aging. 2013; 34:822-831. [PubMed: 22878163]

144. Aizenstein HJ, et al. Frequent Amyloid Deposition Without Significant Cognitive Impairment Among the Elderly. Arch Neurol. 2008; 65:1509-1517. [PubMed: 19001171]

145. Rentz DM, et al. Cognition, reserve, and amyloid deposition in normal aging. Ann. Neurol. 2010; 67:353-364. [PubMed: 20373347]

146. Resnick SM, et al. Longitudinal cognitive decline is associated with fibrillar amyloid-beta measured by [11C]PiB. Neurology. 2010; 74:807-815. [PubMed: 20147655] 
147. Storandt M, Mintun MA, Head D, Morris JC. Cognitive decline and brain volume loss as signatures of cerebral amyloid-beta peptide deposition identified with Pittsburgh compound B: cognitive decline associated with Abeta deposition. Arch Neurol. 2009; 66:1476-1481. [PubMed: 20008651]

148. Ellis KA, et al. Decline in Cognitive Function over 18 Months in Healthy Older Adults with High Amyloid-beta. J. Alzheimers Dis. 2013

149. Lim YY, et al. Rapid Decline in Episodic Memory in Healthy Older Adults with High Amyloidbeta. J. Alzheimers Dis. 2013; 33:675-679. [PubMed: 23001710]

150. Elias MF, et al. The preclinical phase of alzheimer disease: A 22-year prospective study of the Framingham Cohort. Arch Neurol. 2000; 57:808-813. [PubMed: 10867777]

151. Saxton J, et al. Preclinical Alzheimer disease: neuropsychological test performance 1.5 to 8 years prior to onset. Neurology. 2004; 63:2341-2347. [PubMed: 15623697]

152. Wilson RS, Leurgans SE, Boyle PA, Bennett DA. Cognitive Decline in Prodromal Alzheimer Disease and Mild Cognitive Impairment. Archives of Neurology. 2011; 68:351-356. [PubMed: 21403020]

153. Sperling R, Donohue M, Aisen P. The A4 trial: Anti-amyloid treatment of asymptomatic Alzheimer's disease. Alzheimers Dement. 2012; 8:425-426.

154. Langbaum JB, et al. Composite cognitive endpoints with improved power to detect presymptomatic Alzheimer's disease treatment effects in APOE4 carriers: Findings from the Alzheimer's prevention initiative. Alzheimers Dement. 2011; 7:S502.

155. Ayutyanont N, et al. Composite cognitive endpoints with improved power to detect presymptomatic Alzheimer's disease treatment effects: Findings in the Colombian kindred with the E280A Presenilin 1 mutation and the Alzheimer's Prevention Initiative. Alzheimers Dement. 2011; 7:S608.

156. Mosconi L, et al. MCI conversion to dementia and the APOE genotype: a prediction study with FDG-PET. Neurology. 2004; 63:2332-2340. [PubMed: 15623696]

157. Drzezga A, et al. Cerebral metabolic changes accompanying conversion of mild cognitive impairment into Alzheimer's disease: a PET follow-up study. Eur. J. Nucl. Med. Mol. Imaging. 2003; 30:1104-1113. [PubMed: 12764551]

158. de Leon MJ, et al. Longitudinal CSF and MRI biomarkers improve the diagnosis of mild cognitive impairment. Neurobiol Aging. 2006; 27:394-401. [PubMed: 16125823]

159. Jack CR Jr, et al. Serial PIB and MRI in normal, mild cognitive impairment and Alzheimer's disease: implications for sequence of pathological events in Alzheimer's disease. Brain. 2009; 132:1355-1365. [PubMed: 19339253]

160. Dickerson BC, et al. Medial temporal lobe function and structure in mild cognitive impairment. Ann Neurol. 2004; 56:27-35. [PubMed: 15236399]

161. Celone KA, et al. Alterations in memory networks in mild cognitive impairment and Alzheimer's disease: an independent component analysis. J Neurosci. 2006; 26:10222-10231. [PubMed: 17021177]

162. Palop JJ, et al. Aberrant excitatory neuronal activity and compensatory remodeling of inhibitory hippocampal circuits in mouse models of Alzheimer's disease. Neuron. 2007; 55:697-711. [PubMed: 17785178]

163. Jagust WJ, Mormino EC. Lifespan brain activity, beta-amyloid, and Alzheimer's disease. Trends Cogn Sci. 2011; 15:520-526. [PubMed: 21983147]

164. Klunk WE, Mathis CA, Price JC, Lopresti BJ, DeKosky ST. Two-year follow-up of amyloid deposition in patients with Alzheimer's disease. Brain. 2006; 129:2805-2807. [PubMed: 17071918]

165. Li G, et al. CSF tau/Abeta42 ratio for increased risk of mild cognitive impairment: a follow-up study. Neurology. 2007; 69:631-639. [PubMed: 17698783]

166. Forsberg A, et al. PET imaging of amyloid deposition in patients with mild cognitive impairment. Neurobiol Aging. 2008; 29:1456-1465. [PubMed: 17499392]

167. Mattsson N, et al. CSF biomarkers and incipient Alzheimer disease in patients with mild cognitive impairment. JAMA. 2009; 302:385-393. [PubMed: 19622817] 
168. Visser PJ, et al. Prevalence and prognostic value of CSF markers of Alzheimer's disease pathology in patients with subjective cognitive impairment or mild cognitive impairment in the DESCRIPA study: a prospective cohort study. Lancet. Neurol. 2009; 8:619-627. [PubMed: 19523877]

169. Wolk DA, et al. Amyloid imaging in mild cognitive impairment subtypes. Ann Neurol. 2009; 65:557-568. [PubMed: 19475670]

170. Vemuri P, et al. MRI and CSF biomarkers in normal, MCI, AD subjects: Diagnostic discrimination and cognitive correlations. Neurology. 2009; 73:287-293. [PubMed: 19636048]

171. Vemuri P, et al. MRI and CSF biomarkers in normal MCI, and AD subjects: Predicting future clinical change. Neurology. 2009; 73:294-301. [PubMed: 19636049]

172. van Rossum IA, et al. Injury markers predict time to dementia in subjects with MCI and amyloid pathology. Neurology. 2012; 79:1809-1816. [PubMed: 23019259]

173. Prestia A, et al. Prediction of dementia in MCI patients based on core diagnostic markers for Alzheimer disease. Neurology. 2013; 80:1048-1056. [PubMed: 23390179]

174. Roe CM, et al. Amyloid imaging and CSF biomarkers in predicting cognitive impairment up to 7.5 years later. Neurology. 2013

175. Andrews KA, et al. Atrophy rates in asymptomatic amyloidosis: implications for Alzheimer prevention trials. PLoS. One. 2013; 8:e58816. [PubMed: 23554933]

176. Fleisher AS, et al. Using Positron Emission Tomography and Florbetapir F 18 to Image Cortical Amyloid in Patients With Mild Cognitive Impairment or Dementia Due to Alzheimer Disease. Arch Neurol. 2011

177. Fox NC, et al. Effects of Ab immunization (AN1792) on MRI measures of cerebral volume in Alzheimer disease. Neurology. 2005; 64:1563-1572. [PubMed: 15883317] 


\section{Key points}

- The pathogenic cascade of Alzheimer disease (AD) is thought to begin at least 1-2 decades prior to cognitive impairment

- Disappointing results of several AD drugs in late-stage development have suggested the need for early therapeutic intervention, calling for development of biomarkers and sensitive cognitive measures for preclinical disease. The better established measurements for detection and tracking of preclinical and clinical stages of AD include MRI, fluorodeoxyglucose PET, amyloid PET, and cerebrospinal fluid measures of $\mathrm{A} \beta_{42}$, total tau, and phospho-tau

- Individuals at genetic risk of $\mathrm{AD}$ can provide insights into cognitive and biomarker changes that precede clinical manifestation of $\mathrm{AD}$, and are suitable candidates for ongoing monitoring and early-intervention strategies

- We are entering an era of $\mathrm{AD}$ prevention research, with a number of preclinical $\mathrm{AD}$ treatment trials in the planning stages or under way for several at-risk, cognitively unimpaired populations 
Box 1. Biomarkers of Alzheimer disease

Markers of amyloid- $\beta$ accumulation

Amyloid- $\beta$ in cerebrospinal fluid

PET amyloid imaging using ${ }^{11} C$-Pittsburgh compound $B$ or ${ }^{18} \mathrm{~F}$ radiotracers to bind to fibrillar amyloid- $\beta$

Markers of neurodegeneration

Tau and phospho-tau in cerebrospinal fluid

Markers of neuronal activity

Functional MRI measures of task-based neuronal activation, and resting neuronal connectivity

Markers of neuronal loss

MRI measures of cortical thinning, hippocampal volume, and whole-brain volume

Markers of synaptic dysfunction

${ }^{18}$ F-fluorodeoxyglucose PET 


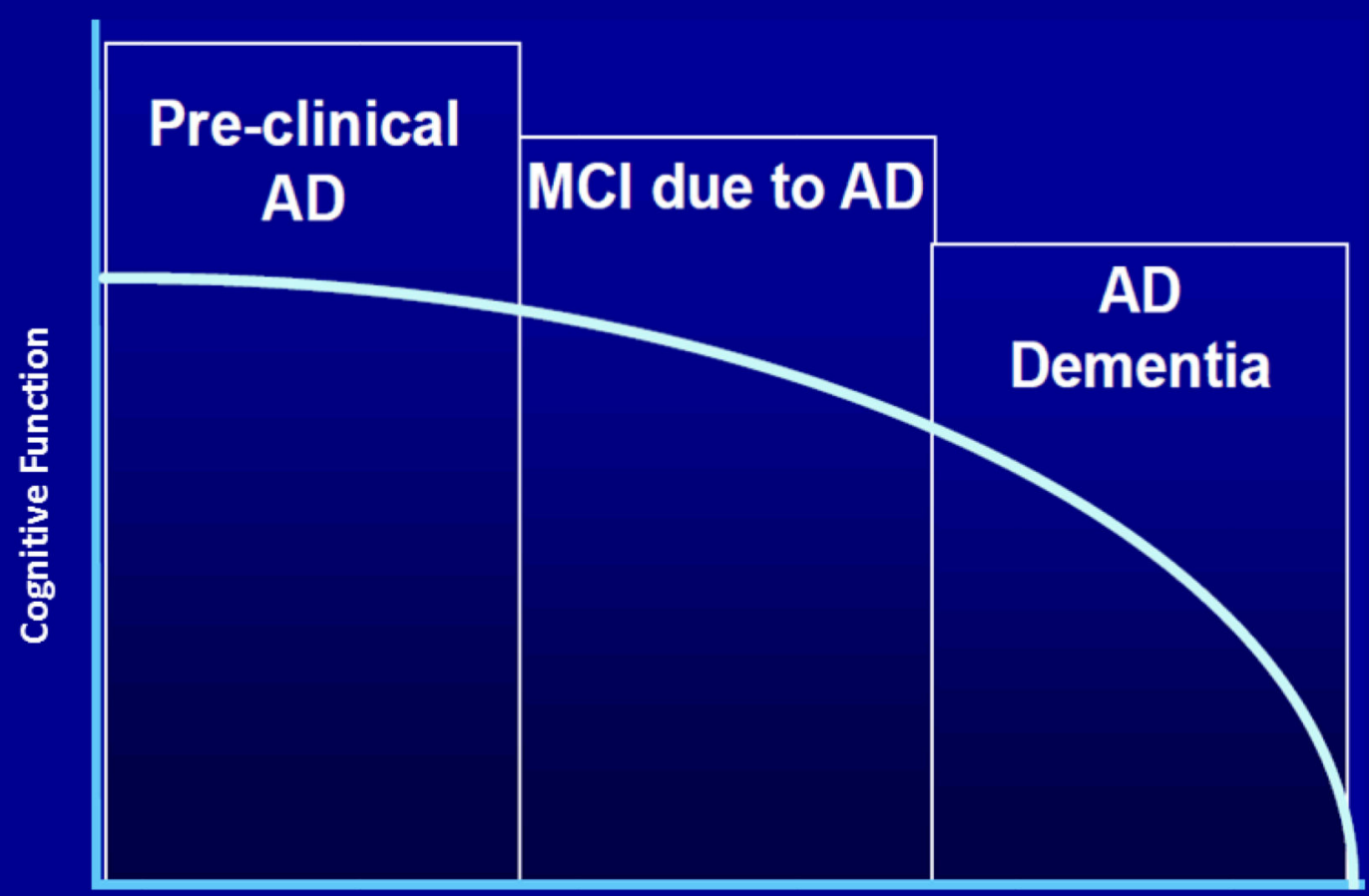

Biological Disease Progression

Figure 1.

Reconceptualizing Alzheimer's Disease 

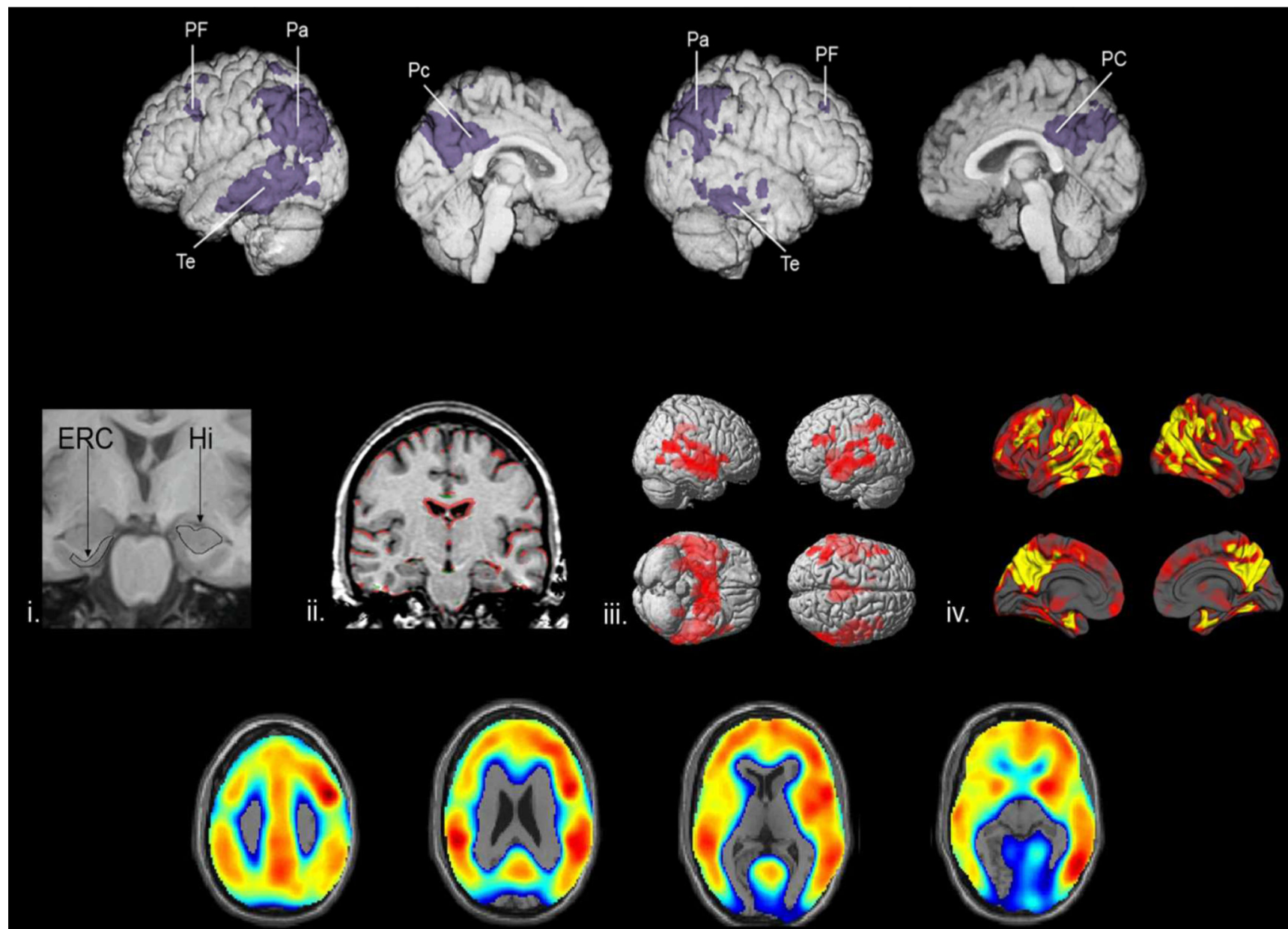

Figure 2.

Well Established Brain Imaging Techniques in the Detection and Tracking of AD 


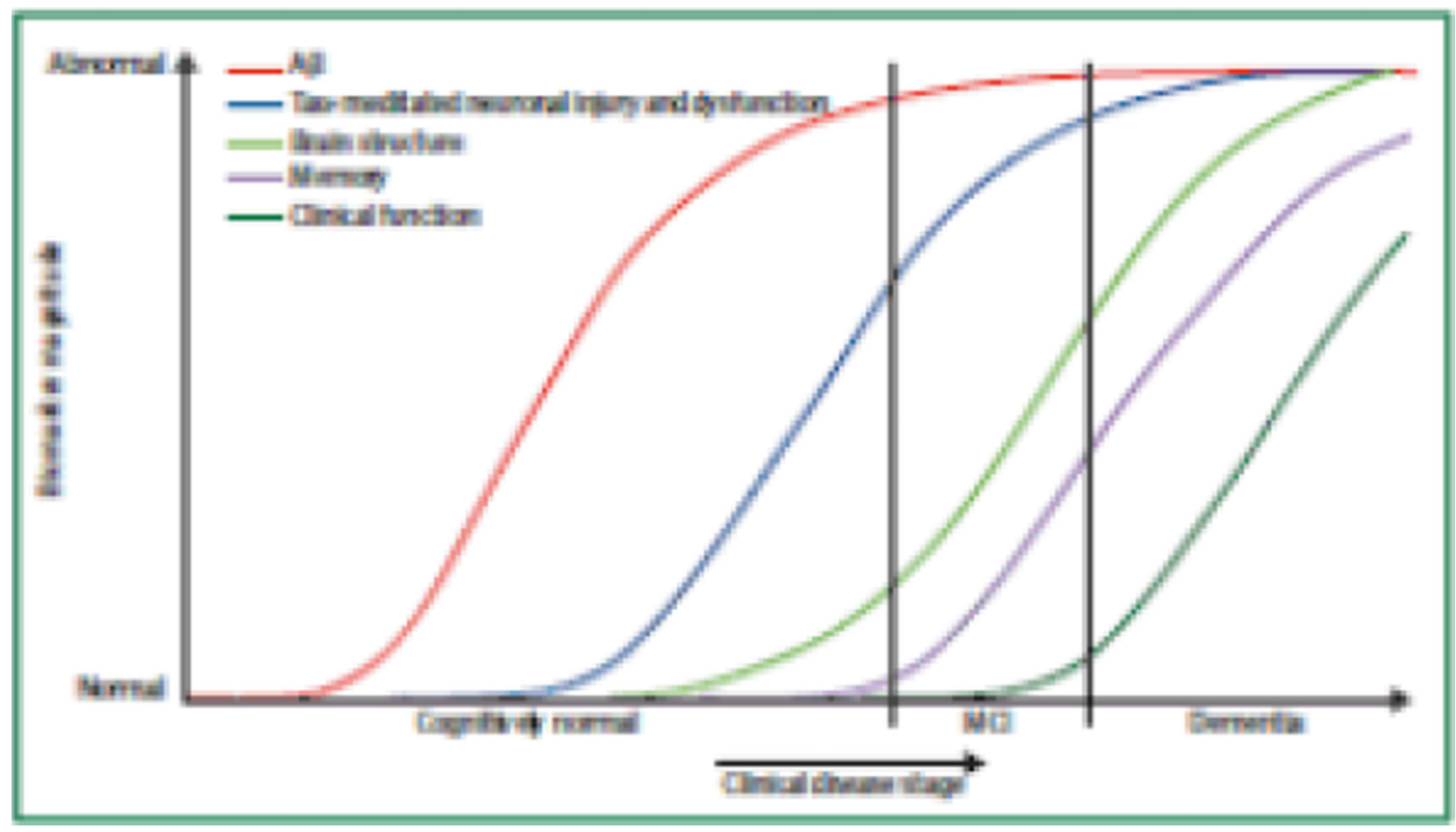

Figure 3.

Hypothetical dynamic biomarkers of the AD pathological cascade ${ }^{12}$ 


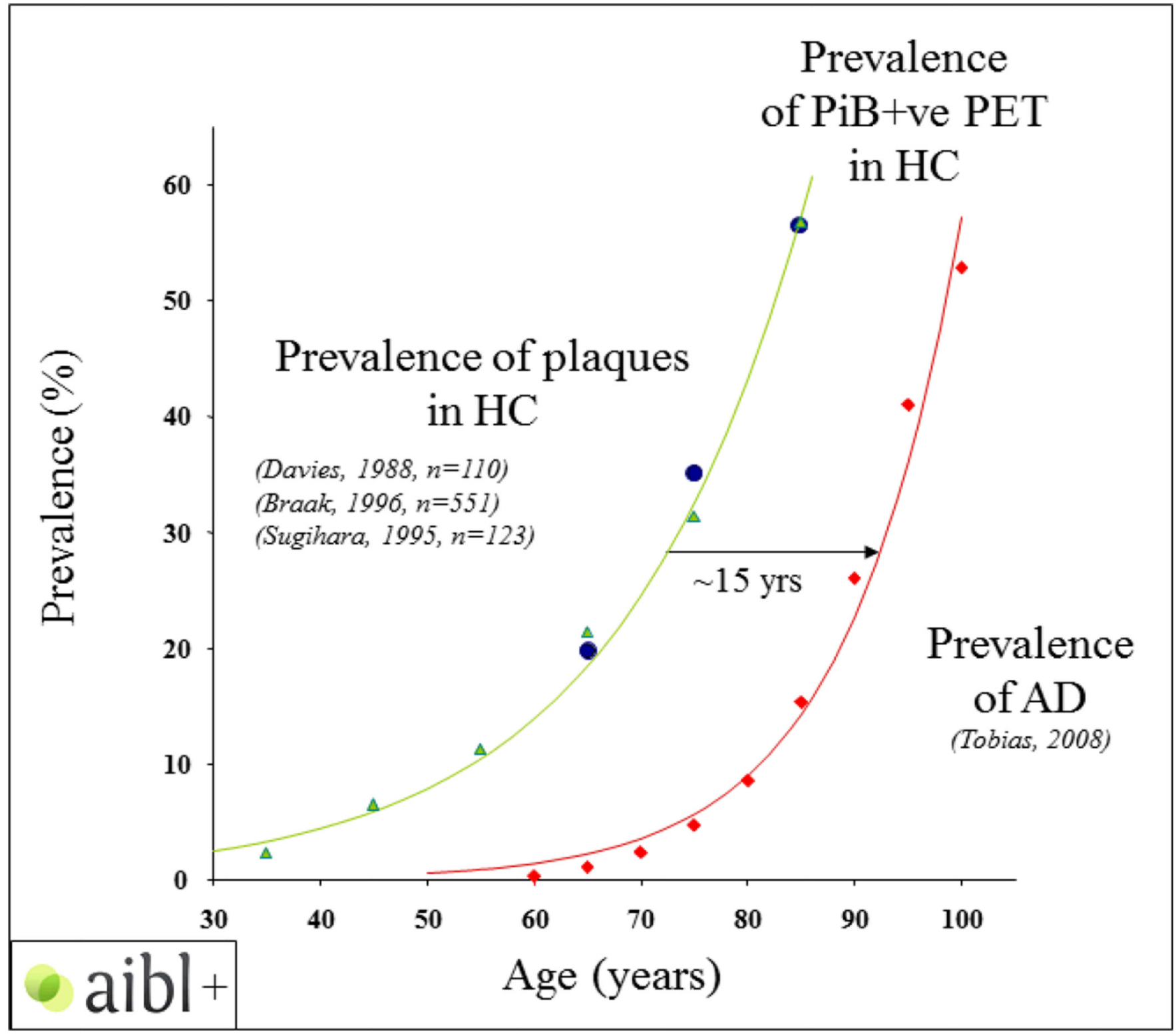

Figure 4.

Temporal link between amyloid deposition and onset of AD dementia With permission from Chris Rowe, reprinted from ${ }^{69}$ 


\section{Table 1}

Staging of preclinical $\mathrm{AD}^{21}$

\begin{tabular}{|l|l|l|l|l|}
\hline Stage & Pathological features & \multicolumn{3}{|l|}{ Biomarkers } \\
\cline { 3 - 5 } & & $\begin{array}{l}\text { Amyloid- } \beta \\
\text { (PET or CSF) }\end{array}$ & $\begin{array}{l}\text { Neurodegeneration } \\
\text { (tau, FDG, MRI) }\end{array}$ & $\begin{array}{l}\text { Cognitive } \\
\text { change }\end{array}$ \\
\hline 1 & Asymptomatic amyloidosis & Present & Absent & Absent \\
\hline 2 & Asymptomatic amyloidosis and neurodegenration & Present & Present & Absent \\
\hline 3 & Asymptomatic amyloidosis, neurodegenration and subtle cognitive decline & Present & Present & Positive \\
\hline
\end{tabular}

Abbreviations: CSF, cerebrospinal fluid; FDG, fluorodeoxyglucose. 